\title{
Modified autologous transobturator tape surgery - evaluation of short term results
}

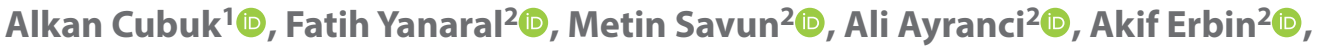

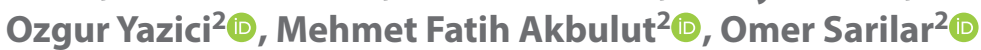 \\ ${ }^{1}$ Dr. Lutfi Kırdar Kartal Training and Research Hospital, Istanbul, Turkey \\ ${ }^{2}$ Haseki Training and Research Hospital, Istanbul, Turkey
}

\begin{abstract}
Objectives: The aim of this study is to evaluate the short-term outcomes of our modified autologous transobturator tape (aTOT) technique with rectus abdominis muscle fascial graft for the treatment of female stress urinary incontinence (SUI).

Material and methods: The data of 22 patients who underwent modified aTOT were recorded. Perioperative data regarding operative time, complications and postoperative visual analogue scores were noted. Patients were assessed 18 months after surgery. The primary endpoints of this study were the improvements in the International Consultation on Incontinence Questionnaire-Female Lower Urinary Tract Symptoms (ICIQ-FLUTS) subscores, one-hour pad test and cough stress test rates as an objective cure as well as the improvements in the PGI-I and ICIQ-FLUTS quality of life scores as a subjective cure. Results: Mean age and the mean follow-up period were $51.7 \pm 9.8$ years and $20.1 \pm 0.9$ months, respectively. Urethral hypermobility and a positive cough stress test were detected in all the patients. Mean operative time was $43.8 \pm 8.1 \mathrm{~min}$. and the overall complication rate was $9 \%$. Mean VAS scores at postoperative 24 hours were $2.6 \pm 1.2$. At the postoperative eighteenth month, no patient had a positive cough test and mean PGI-I score was 2 while two patients had moderate urinary incontinence according to the pad test. Pad test results, ICIQ subscores of voiding QoL, incontinence, incontinence QoL, total score and total QoL score at baseline and eighteen months after surgery were $76.9 \pm 19.9,9.6 \pm 4.1,15.5 \pm 4.0$, $39.5 \pm 7.9,27.9 \pm 6.6,68.4 \pm 13.8$ and $7.1 \pm 2,10.1 \pm 2.4,6.6 \pm 2.1,13.4 \pm 4.5,20.4 \pm 4.8,39.7 \pm 9.2$ respectively $(p=0.001$ $p=0.004, p=0.001, p=0.001, p=0.001$, and $p=0.001$, respectively)
\end{abstract}

Conclusions: Modified aTOT is an effective and safe method with low morbidity for SUI treatment in short term.

Key words: stress urinary incontinence; mid-urethral sling surgery; mesh; complication

Ginekologia Polska 2020; 91, 2: 51-56

\section{INTRODUCTION}

Mid-urethral sling surgeries (MUSS): transobturator-tape (TOT) and retro-pubic tape (RT) with a non-absorbable synthetic material are the most common surgical procedures for female stress urinary incontinence (SUI) [1]. The advantages of these procedures include a reduced operative time, a favorable outpatient technique and promising long-term outcomes [2]. Nevertheless, a number of unique mesh-related complications such as erosion, migration and mesh site infection have been reported in up to $2 \%$ of the cases undergoing MUSS and these complications require surgical intervention to revise or remove the mesh $[3,4]$.

The United States Food and Drug Administration (FDA) released public health notifications about mesh usage in transvaginal surgeries. FDA classified meshes as class 3 devices (highest risk devices) for pelvic organ prolapse (POP) surgery and class 2 for SUI surgery [5]. FDA also noted that MUSS are less morbid surgeries, have similar cure rates with non-mesh surgeries and cause unique complications that are not present in non-mesh surgeries. Although these reports did not limit the use of mesh for SUI, MUSS has been increasingly questioned by patients, surgeons and legal communities after the emergence of these reports [6]. Moreover, television advertisements and litigation related to mesh complications have increased since the FDA reports. Although the complication rates remain stable after MUSS, the frequency of symptoms reported by patients has increased recently [1]. 
Current guidelines still recommend MUSS for SUI treatment [7] However, numerous non-mesh techniques have been described for SUI surgery over the last decade after FDA warnings. Accordingly, traditional pubovaginal slings (PVS) using autologous rectus muscle fascia have been re-popularized $[8,9]$. Moreover, Burch colposuspension surgery $(\mathrm{BC})$ has been shown as a viable option for recurrent and primary SUI and urethral bulking agents have re-emerged as popular techniques $[10,11]$. A number of new techniques using autologous tissues based on the surgical characteristics of MUSS have been described to avoid mesh-related complications [1, 12-13]. However, there is no consensus on an optimal surgical technique for SUI surgery in patients who are unwilling to undergo mesh surgery.

\section{Objectives}

MUSS with autologous tissue appears to be a feasible option although there is a need for further documentation of the benefits of this technique as well as its short- and long-term outcomes. The present study aimed to evaluate the outcomes of our modified autologous transobturator tape (aTOT) technique in patients with SUI.

\section{MATERIAL AND METHODS}

\section{Study population}

After obtaining an approval from the Institutional Review Board, the study evaluated a total of 22 female patients that underwent modified aTOT for SUI between December 2017 and February 2018. All the patients met the criteria for uncomplicated SUI and the exclusion criteria included POP greater than grade 2 according to the Pelvic Organ Prolapse Quantification (POP-Q) system, pregnancy, history of pelvic radiation and SUI surgery, increased post-void residual volume (PVRV) (greater than $150 \mathrm{cc}$ ), poor voiding patterns on uroflowmetry and history of neurologic diseases. Patients were encouraged for lifestyle modification and pelvic floor muscle training for a minimum period of three months after the diagnosis of SUI. Indications for surgery included reluctance or dissatisfaction after conservative management. The available surgical options and the concerns about synthetic meshes were discussed with patients. Modified aTOT was performed in each patient who preferred to undergo MUSS but refused the use of synthetic meshes and accepted to participate in this study protocol.

\section{Diagnostic workup}

Patients were evaluated based on a detailed medical history, urine culture, pelvic examination including urethral hypermobility test (Q-tip test), cough stress test (CST) and POP examination and uroflowmetry with measurement of PVRV. The Q-tip test was performed in lithotomy position; a well-lubricated cotton-tipped swab was introduced into the urethra and then resting and straining angles were measured at the horizontal plane. A straining angle greater than $30^{\circ}$ was a threshold for urethral hypermobility [14]. CST was performed in the lithotomy position with $200-400 \mathrm{ml}$ urine in bladder; urine leakage from urethra after one to three strong coughs was associated with a positive result [12].

The International Consultation on Incontinence Questionnaire-Female Lower Urinary Tract Symptoms (ICIQ-FLUTS), which is a validated form used for the evaluation of lower urinary tract symptoms and quality of life (QoL) in three sections (frequency, voiding, and incontinence) was administered to each patient. The one-hour pad test, which is standardized by the International Continence Society (ICS) as the measurement of pad weight increase after a standard protocol, was used for the objective assessment of SUI. The weight gain of the pad was recorded and the degree of incontinence was classified into three groups as; mild (1-10 g), moderate (10-50 g) and severe (> $50 \mathrm{~g})$ [15]. Patients diagnosed with SUI and also suffering from urinary incontinence with urgency were classified as mixed urinary incontinence (MUI).

\section{Surgical technique}

Our surgical technique was elaborated in a previous article [16]. After the induction of general anesthesia, the patient was positioned in the lithotomy position and a Foley catheter was inserted. After hydrodissection with saline, a $2 \mathrm{~cm}$ longitudinal vaginal incision was performed at the mid-urethral level. Bilateral periurethral dissection was performed until reaching the inferior ischiopubic ramus. A 5 * $1.5 \mathrm{~cm}$ rectus fascia was harvested via a $3 \mathrm{~cm}$ suprapubic transverse incision. Two 2-0 nonabsorbable polyester stay sutures (Ethibond ${ }^{\oplus}$, Ethicon) were placed on the corners of the fascial graft on both sides. Two separate punctures were performed on both sides over the medial aspect of the obturator foramen at the level of the clitoris and the dissection was continued to the obturator foramen blindly. A TOT needle was passed twice through the foramen and the stitches were transferred from the vaginal incision to the skin separately. A bridge was established on the obturator membrane by separate stitches on both sides. The graft was placed in the mid-urethral position without tension and sutures were tied to each other on both sides. We didn't perform intraoperative cough test. The incisions were closed separately and a vaginal packing was placed at the end of the procedure. The urethral catheter and vaginal packing were removed and the patient was discharged at the first postoperative day.

\section{Follow-up}

Perioperative data regarding operative time and complications were recorded for each patient. Complications were 
Table 1. Patients' characteristics

\begin{tabular}{|l|l|}
\hline Age $[$ year] & $51.7 \pm 9.8$ \\
\hline BMI $\left[\mathbf{k g} / \mathbf{m}^{2}\right]^{*}$ & $28.8 \pm 3.9$ \\
\hline Number of births* & $3.2 \pm 1.2$ \\
\hline Vaginal birth* & $2.9 \pm 1.6$ \\
\hline Cesarean* & $0.4 \pm 0.8$ \\
\hline Assisted vaginal birth** & NA \\
\hline Pelvic surgery history & $1(4.5 \%)$ \\
\hline Menopause & $9(40.9 \%)$ \\
\hline Incontinence (pure stress/mixed) & $16 / 6$ \\
\hline Diabetes mellitus & $2(9.1 \%)$ \\
\hline
\end{tabular}

* - mean + standard deviation; ** - births with vacuum and forceps devices; $\mathrm{NA}$ - not available; BMI — body mass index

Table 2. Operative and post-operative data

\begin{tabular}{|l|l|}
\hline Operation time [minutes] & $43.8 \pm 8.1$ \\
\hline VAS score (post op 8. hours)* & $6.2 \pm 0.8$ \\
\hline VAS score (post op 24. hours)* & $2.6 \pm 1.2$ \\
\hline Complication & \\
\hline Grade 1 & $2(9 \%)$ \\
\hline Grade 2 & 0 \\
\hline Grade 3 & 0 \\
\hline Duration of follow up (months)* & $20.1 \pm 0.9$ \\
\hline
\end{tabular}

* - mean + standard deviation

\begin{tabular}{|c|c|c|c|}
\hline & Baseline & $18^{\text {th }}$ months & $p$ \\
\hline ICIQ Frequency* & $8.1 \pm 2.8$ & $8.4 \pm 2.8$ & 0.557 \\
\hline ICIQ Frequency QoL* & $19.3 \pm 7.3$ & $16.3 \pm 5.7$ & 0.156 \\
\hline ICIQ Voiding * & $4.2 \pm 2.3$ & $5.3 \pm 1.4$ & 0.095 \\
\hline ICIQ Voiding QoL* & $9.6 \pm 4.1$ & $10.1 \pm 2.4$ & 0.004 \\
\hline ICIQ Incontinence* & $15.5 \pm 4.0$ & $6.6 \pm 2.1$ & 0.001 \\
\hline ICIQ Incontinence QoL* & $39.5 \pm 7.9$ & $13.4 \pm 4.5$ & 0.001 \\
\hline ICIQ Total Score* & $27.9 \pm 6.6$ & $20.4 \pm 4.8$ & 0.001 \\
\hline ICIQ Total QoL Score* & $68.4 \pm 13.8$ & $39.7 \pm 9.2$ & 0.001 \\
\hline Ped Test [gr/hour]* & $76.9 \pm 29.9$ & $7.1 \pm 2$ & 0.001 \\
\hline Stress Test + & 22 & 0 & 0.001 \\
\hline
\end{tabular}

* - mean + standard deviation

evaluated and classified based on the Clavien system [17]. Visual analogue score (VAS) was performed for pain assessment at postoperative hours 8 and 24 . All the patients were discharged at the first postoperative day after spontaneously voiding at least two-thirds of the total bladder volume as confirmed by ultrasonography. At the first postoperative week, patients were invited for a clinical evaluation of surgical wounds and the assessment of surgery-related problems.

During the follow-up, patients were evaluated at $1^{\text {st }}$, $3^{\text {rd }}, 6^{\text {th }}$ and $18^{\text {th }}$ months after surgery. At the postoperative eighteenth months, patients were evaluated with stress test, the one-hour pad test, ICIQ-FLUTS and the Patient Global Impression of Improvement (PGI-I) scale. For each patient the necessity of further surgery due to complications or failure was noted.

The primary endpoints of this study were the improvements in the ICIQ-FLUTS subscores, one-hour pad test and cough stress test rates as an objective cure as well as the improvements in the PGI-I and ICIQ-FLUTS quality of life scores as a subjective cure.

\section{Statistical analysis}

Data were analyzed using Statistical Package for Social Sciences (SPSS) for Windows version 20.0 (Armonk, NY: IBM Corp.). Categorical variables were presented as frequencies ( $\mathrm{n}$ ) and percentages (\%). Continuous variables were presented as mean \pm standard deviation (SD) and were compared using a paired Student's $t$-test. A two-tailed $p$ value of $<0.05$ was considered significant.

\section{RESULTS}

The 22 patients with a mean age of $51.7 \pm 9.8$ years enrolled in this study. Preoperatively, $16(72.7 \%)$ patients had pure SUI and 6 (27.3\%) patients had stress-dominant MUI (Tab. 1). Mean follow-up period was $20.1 \pm 0.9$ months.

Urethral hypermobility and a positive cough stress test were detected in all the patients. Mean pad weight gain was $76.9 \pm 19.9 \mathrm{~g}$ in the one-hour pad test and the test also showed moderate and severe urinary incontinence in $6(27.3 \%)$ and 16 (72.7\%) patients, respectively. Mean operative time was $43.8 \pm 8.1 \mathrm{~min}$ and the overall complication rate was $9 \%$ (2/22) (Clavien Grade 1). One patient had wound infection on suprapubic incision and one had vaginal exposure of fascial graft smaller than $1 \mathrm{~cm}$. Both patients were treated conservatively without any further surgical intervention. Mean VAS scores at postoperative hours 8 and 24 were $6.2 \pm 0.8$ and $2.6 \pm 1.2$, respectively (Tab. 2 ). No patient was diagnosed with urinary retention and urogenital tract infection during the follow up period.

Table 3 presents a comparison of pre- and post-operative findings. In the postoperative eighteenth month, no patient had a positive cough test. Mean pad weight gain was 76.9 vs $7.1 \mathrm{gr}$ in the pad test at baseline and postoperative eighteenth month, respectively $(p=0.001)$. Two patients had moderate urinary incontinence at postoperative eighteenth month according to pad test. The mean PGI-I score was 2 postoperatively. ICIQ subscores of voiding QoL, incontinence, incontinence QoL, total score and total QoL 
score at baseline and eighteen months after surgery were $9.6 \pm 4.1,15.5 \pm 4.0,39.5 \pm 7.9,27.9 \pm 6.6,68.4 \pm 13.8$, and $10.1 \pm 2.4,6.6 \pm 2.1,13.4 \pm 4.5,20.4 \pm 4.8,39.7 \pm 9.2$ respectively $(p=0.004, p=0.001, p=0.001, p=0.001$, and $p=0.001$, respectively). At postoperative eighteenth month patients had not any complaints about pain.

\section{DISCUSSION}

The subjective cure and postoperative satisfaction rates of MUSS, PVS and BC vary from 62 to $98 \%$ in the literature. This range was associated with the diversity of the definitions of incontinence and also with the tools for measuring patient satisfaction [18]. Ford et al. [19] reported that the average subjective cure rates (improvement in any type of incontinence) for both TOT and RT at the postoperative first and fifth years were $83 \%$ and $84 \%$, respectively. Brubaker et al. [20] further analyzed the findings of their previously published SISTer study and reported that the patients' satisfaction rates after PVS and BC decreased slightly between the second and fifth postoperative years, with a decrease from $79 \%$ to $73 \%$ for BC and from $87 \%$ to $83 \%$ for PVS. In the present study, the subjective cure rate was $100 \%$ according to the PGI-I scores and the improvements in QoL scores. Our findings are comparable with the findings of studies with a follow-up of up to two years; however, longer term findings are needed for a comparison with the findings of studies with longer follow-up periods.

Albo et al. evaluated objective cure rates after SUI surgeries and suggested that despite strict definitions of objective cure such as; negative cough stress test, negative values on one hour or 24 hours pad test and no record of incontinence on three days voiding diaries and urodynamic investigations, it is impossible to compare studies due to variation of these definitions $[20,21]$. Ford et al. reported the objective cure rates at the first and fifth postoperative years as $85 \%$ and $82 \%$ for TOT and as $87 \%$ and $85 \%$ for RT, respectively [19]. Palos et al. reported that the objective cure rates of TOT and RT were $100 \%$ and $92 \%$ at postoperative month 12, respectively [22]. In SISTer trial, Albo et al. [21] reported the objective cure rates for PVS and BC at the second year as $66 \%$ and $49 \%$, respectively. In another study, Maggiori et al [23] reported lower objective cure rates in the fifth year, with $30 \%$ for PVS and $24 \%$ for BC and reported that the majority of the study population probably consisted of the incontinent participants of the previous study. In the present study, objective cure rate was calculated as $100 \%$ based on the one-hour pad test and cough stress test results. This finding implicates that the usage of autologous graft in mid-urethral sling surgery does not reduce the short-term effects of the surgery (up to two years) compared to those of TOT and RT and thus our technique can be considered to provide better outcomes compared to those of $\mathrm{BC}$ and PVS.
The analysis of postoperative outcomes indicated that two patients had moderate urinary incontinence on the one-hour pad test although they had a negative stress test result and a score of $<4$ on PGI-I. Abdelfettah et al. [24] calculated a correlation with $96 \%$ sensitivity and $93 \%$ specificity between self-assessment questionnaires and the one hour pad test. However, Constantini et al [25] suggested that one hour pad test has a poor predictive value in diagnosis of female SUI. At the present study, there was discordance between pad test and the other diagnostic tools. This discordance can also be noted among the guidelines; while EAU guidelines recommend the use of pad test, NICE guidelines do not $[26,27]$.

For the assessment of SUI, detecting urethral hypermobility had an important role in previous literature. Q-type test and voiding cystourethrogram can be used to measure urethral hypermobility [14]. Walsh at al. [14] concluded that although traditionally lower degree of urethral hypermobility indicates intrinsic sphincter deficiency and PVS is a better option for these patients, nowadays it has been a controversial issue due to the lack of a standardized definition and measurement techniques. Proper positioning of swab into urethra, rigidity of foley catheter and concomitant POP are the factors affecting measurements. Nowadays although current AUA/SUFU and NICE guidelines don't recommend to routinely use urethral hypermobility measurements at the present study it was used not only to detect hypermobility but also to detect fixed urethra which is indicated as an important issue to determine type of incontinence surgery type by Walsh at al $[7,14]$.

Fusco et al. [28] conducted a meta-analysis and reported that incontinence surgery resulted in a significant improvement in the QoL measurements of the patients regardless of the surgical technique. Palos et al. [29] suggested that the improvements in QoL measurements are correlated with the objective and subjective cure rates. In the present study, significant improvements were also observed in the QoL scores for the incontinence subsection and the total QoL score of ICIQ-FLUTS for all patients and it was also correlated with the continence status of the patients.

Literature indicates that PVS, BC and MUSS have similar complication rates [29-32]. For instance, perioperative bleeding requiring blood transfusion is a serious problem associated with all of these procedures and may occur in up to $2 \%$ of the cases [29-32]. In the present study, however, no patient had significant blood loss. Another feared complication of these three techniques is bowel, bladder or urethral injury which has been reported in up to $9 \%$ of the cases [29-32]. Higher rates were reported after RT procedures for bladder, vascular and bowel injuries [18]. In contrast, TOT provides technical advantages in terms of avoiding perioperative organ injury and has been reported to cause bladder or urethra injury in only a limited number 
of cases [19]. In our study, no perioperative organ injury was observed in any patient.

Blavias et al. [30] reported the wound complications rate as 3\% after PVS. In our study, only one patient (4\%) was diagnosed with wound infection and was treated with non-surgical interventions. A biological graft material is needed to avoid the use of synthetic mesh and a Cochrane review by Rehman et al. [33] suggested that rectus muscle fascia is the most appropriate and most commonly preferred material for PVS. Mahdy et al. [31] suggested the use of fascia lata when it is impossible to harvest rectus fascia. In our study, no material other than rectus fascia was required in any patient. In our opinion, it is easy to harvest this fascia and usually patients have an incision secondary to previous cesarean or other surgical interventions; therefore, it can be performed via this incision to avoid a new incision and scar on patients. Blavias et al. [25] reported chronic pelvic pain in $0.6 \%$ of the patients. Pelvic pain rates were $0.8 \%$ and $2.9 \%$ while groin pain rates were $6.4 \%$ and $0.6 \%$ for TOT and RT, respectively [18]. The decrease in VAS scores of our patients indicates that this pelvic pain disappeared at postoperative first day. This result is comparable with literature; however we have no data about groin pain.

Erosion of mesh into the vagina, bladder, or urethra is a complication of MUSS, which has been reported in $0.7-2 \%$ of the cases [2]. No differences were reported among the TOT and RT procedures [18]. The etiological factors of this complication include inadequate vaginal closure, wound infection, early sexual intercourse and excessive tension of the sling. In contrast, PVS do not cause mesh erosions due to its autologous structure $[8,28]$. In our study, no erosion was observed, however only one patient had a minimal vaginal exposure of fascial graft that was smaller than $1 \mathrm{~cm}$, which was successfully treated with topical estradiol. Based on these findings, we consider that the usage of autologous graft with proper tension is of critical importance for obtaining favorable outcomes.

Abraham et al. [34] suggested that the symptoms of de novo urgency are as bothersome for the patients as the symptoms of preoperative stress urinary incontinence. Mahdy et al. [31] reported the incidences of de novo urgency and urge incontinence after PVS as $15-20 \%$ and $7.2 \%$, respectively. On the other hand, a similar incidence of de novo urgency has been reported for BC and MUSS (10\%), more common after RT than TOT [18, 30]. Gomez et al. suggested that bladder outlet obstruction, bladder perforation and infection are the major causes of de novo urgency [35]. In our study, no significant change was observed between pre- and post-operative scores of the frequency subsection of ICIQ-FLUTS. We consider that although MUSS are thought to be tension-free procedures, fibrosis secondary to mesh placement can cause urethral obstruction in the long term; thereby leading to de novo urgency [19, 35]. Accordingly, we suggest that autologous graft positioned in the mid-urethral region without tension will not cause de novo urgency. It can be explained by lower possibility of urethral obstruction owing to the very low fibrosis potential of autologous graft around the urethra when compared to synthetic meshes and by the lack of bladder neck obstruction secondary to the mid-urethral positioning of fascial graft when compared to PVS.

Voiding dysfunction and urinary retention requiring urethral catheterization are two well-known complications reported after SUI surgery and have been shown to be associated with urinary bladder detrusor dysfunction and iatrogenic urethral obstruction [30-33]. The incidence of urinary retention after PVS, BC and MUSS has been reported to be $20 \%, 8 \%$, and $3 \%$, respectively [ $19,31-32]$. In our study, no patient had urinary retention and there was no significant difference between pre- and post-operative scores of the voiding subsection of ICIQ-FLUTS. These findings could be attributed to two factors: the adequate preoperative detrusor contractility of all the patients assessed by uroflowmetry (patients with intermittent flow patterns and high residual urine volumes were not included in the study) and the tension-free nature of our technique.

Veit-Rubin et al. [10] detected POP in $25 \%$ of the patients that underwent BC. In contrast, PVS, MUSS and also the method used in the present study have no risk of POP formation as they do not require pelvic dissection which distorts urethral support during surgery, as in $B C[28,29]$.

To our knowledge, the use of autologous tissue in MUSS has been investigated in a small patient series with short-term results [1, 12-13]. El-Gamal et al. used a hybrid mesh for TOT in 44 patients, which was an elongated rectus fascia with synthetic non-absorbable mesh on both edges [12]. The cure rates were remarkably high (92\%) and the complication rates were comparable with MUSS however their method could not be considered as a non-mesh surgery. Linder et al. developed an autologous transobturator sling technique [1]. They reported retreatment-free survival rate as $75 \%$ in the postoperative 18 months. The authors used an absorbable suture to elongate the rectus fascia and in our opinion after breaking down of these sutures, autologous tissue lost its tension and position [1]. This problem might be a cause of long-term treatment failure. Osman et al. described a novel technique called'sling on a string', in which rectus fascia is positioned as a classic RT mesh. The authors published their results from 106 patients with a follow-up of 9 months and reported that their results were comparable to those of MUSS although their technique resulted in longer hospital stays (5.6 days) [13].

The present study contributes to the literature in terms of surgical modifications. However, it had some limitations 
such as short follow-up period, small number of patients and the absence of cost analysis.

\section{CONCLUSIONS}

Modified aTOT is an effective and safe method with low morbidity for SUI treatment in short term.

\section{REFERENCES}

1. Linder BJ, Elliott DS. Autologous Transobturator Urethral Sling Placement for Female Stress Urinary Incontinence: Short-term Outcomes. Urology. 2016; 93: 55-59, doi: 10.1016/j.urology.2016.03.025, indexed in Pubmed: 27036519.

2. Gomes $\mathrm{CM}$, Carvalho FL, Bellucci $\mathrm{CH}$, et al. Update on complications of synthetic suburethral slings. Int Braz J Urol. 2017; 43(5): 822-834, doi: 10.1590/S1677-5538.IBJU.2016.0250, indexed in Pubmed: 28266818.

3. Linder BJ, El-Nashar SA, Carranza Leon DA, et al. Predictors of vaginal mesh exposure after midurethral sling placement: a case-control study. Int Urogynecol J. 2016; 27(9): 1321-1326, doi: 10.1007/s00192-016-29472, indexed in Pubmed: 26811112.

4. Chughtai B, Barber MD, Mao J, et al. Association Between the Amount of Vaginal Mesh Used With Mesh Erosions and Repeated Surgery After Repairing Pelvic Organ Prolapse and Stress Urinary Incontinence. JAMA Surg. 2017; 152(3): 257-263, doi: 10.1001/jamasurg.2016.4200, indexed in Pubmed: 27902825.

5. United States Food and Drug Administration: Considerations about surgical mesh for SUl. https://www.fda.gov/MedicalDevices/ProductsandMedicalProcedures/ImplantsandProsthetics/UroGynSurgicalMesh/ucm345219.htm (01.2018).

6. Chapple $C R, \operatorname{Raz} S$, Brubaker $L$, et al. Mesh sling in an era of uncertainty: lessons learned and the way forward. Eur Urol. 2013; 64(4): 525-529, doi: 10.1016/j.eururo.2013.06.045, indexed in Pubmed: 23856039.

7. Syan R, Brucker BM. Guideline of guidelines: urinary incontinence. BJU Int. 2016; 117(1):20-33, doi: 10.1111/bju.13187, indexed in Pubmed: 26033093.

8. Ghoniem GM, Rizk DEE. Renaissance of the autologous pubovaginal sling. Int Urogynecol J. 2018; 29(2): 177-178, doi: 10.1007/s00192-0173521-2, indexed in Pubmed: 29167973.

9. Bailly GG, Carlson KV.The pubovaginal sling: Reintroducing an old friend. Can Urol Assoc J. 2017; 11(6Suppl2): S147-S151, doi: 10.5489/cuaj.4611, indexed in Pubmed: 28616116.

10. Veit-Rubin N, Dubuisson J, Ford A, et al. Burch colposuspension. Neurourol Urodyn. 2019; 38(2): 553-562, doi: 10.1002/nau.23905, indexed in Pubmed: 30620096.

11. Zacche MM, Mukhopadhyay S, Giarenis I. Changing surgical trends for female stress urinary incontinence in England. Int Urogynecol J. 2019; 30(2): 203-209, doi: 10.1007/s00192-018-3839-4, indexed in Pubmed: 30523375.

12. El-Gamal O, Soliman M, Tawfik A, et al. Use of autologous rectus fascia in a new transobturator hybrid sling for treatment of female stress urinary incontinence: a pilot study. Scand J Urol. 2013; 47(1): 57-62, doi: 10.3109/00365599.2012.700319, indexed in Pubmed: 22793863.

13. Osman NI, Hillary CJ, Mangera A, et al. The Midurethral Fascial "Sling on a String": An Alternative to Midurethral Synthetic Tapes in the Era of Mesh Complications. Eur Urol. 2018; 74(2): 191-196, doi: 10.1016/j. eururo.2018.04.031, indexed in Pubmed: 29803585.

14. Walsh LP, Zimmern PE, Pope N, et al. Urinary Incontinence Treatment Network. Comparison of the Q-tip test and voiding cystourethrogram to assess urethral hypermobility among women enrolled in a randomized clinical trial of surgery for stress urinary incontinence. JUrol. 2006; 176(2): 646-649; discussion 650, doi: 10.1016/j.juro.2006.03.091, indexed in Pubmed: 16813912.

15. D'Ancona C, Haylen B, Oelke M, et al. Standardisation Steering Committee ICS and the ICS Working Group on Terminology for Male Lower Urinary Tract \& Pelvic Floor Symptoms and Dysfunction. The International Continence Society (ICS) report on the terminology for adult male lower urinary tract and pelvic floor symptoms and dysfunction. Neurourol Urodyn. 2019; 38(2): 433-477, doi: 10.1002/nau.23897, indexed in Pubmed: 30681183.

16. Çubuk A, Erbin A, Savun M, et al. Autologous transobturator midurethral sling. Turk J Urol. 2018; 45(3): 230-232, doi: 10.5152/tud.2018.83797, indexed in Pubmed: 31846421.
17. Clavien PA, Barkun J, de Oliveira ML, et al. The Clavien-Dindo classification of surgical complications: five-year experience. Ann Surg. 2009; 250(2): 187-196, doi: 10.1097/SLA.0b013e3181b13ca2, indexed in Pubmed: 19638912.

18. Fusco F, Abdel-Fattah M, Chapple CR, et al. Updated Systematic Review and Meta-analysis of the Comparative Data on Colposuspensions, Pubovaginal Slings, and Midurethral Tapes in the Surgical Treatment of Female Stress Urinary Incontinence. Eur Urol. 2017; 72(4): 567-591, doi: 10.1016/j.eururo.2017.04.026, indexed in Pubmed: 28479203.

19. Ford AA, Rogerson L, Cody JD, et al. Mid-urethral sling operations for stress urinary incontinence in women. Cochrane Database Syst Rev. 2015; 7(7): CD006375, doi: 10.1002/14651858.CD006375.pub3, indexed in Pubmed: 26130017.

20. Brubaker L, Richter HE, Norton PA, et al. Urinary Incontinence Treatment Network. 5-year continence rates, satisfaction and adverse events of burch urethropexy and fascial sling surgery for urinary incontinence. JUrol. 2012; 187(4): 1324-1330, doi: 10.1016/j.juro.2011.11.087, indexed in Pubmed: 22341290.

21. Albo ME, Richter HE, Brubaker L, et al. Urinary Incontinence Treatment Network. Burch colposuspension versus fascial sling to reduce urinary stress incontinence. N Engl J Med. 2007; 356(21): 2143-2155, doi: 10.1056/NEJMoa070416, indexed in Pubmed: 17517855.

22. Palos CC, Maturana AP, Ghersel FR, et al. Prospective and randomized clinical trial comparing transobturator versus retropubic sling in terms of efficacy and safety. Int Urogynecol J. 2018; 29(1): 29-35, doi: 10.1007/s00192-017-3495-0, indexed in Pubmed: 28971224.

23. Leone Roberti Maggiore U, Finazzi Agrò E, Soligo M, et al. Long-term outcomes of TOT and TVT procedures for the treatment of female stress urinary incontinence: a systematic review and meta-analysis. Int Urogynecol J. 2017; 28(8): 1119-1130, doi: 10.1007/s00192-017-3275-x, indexed in Pubmed: 28213797.

24. Abdel-fattah M, Barrington JW, Youssef M. The standard 1-hour pad test: does it have any value in clinical practice? Eur Urol. 2004;46(3):377-380, doi: 10.1016/j.eururo.2004.04.018, indexed in Pubmed: 15306111.

25. Costantini E, Lazzeri M, Bini V, et al. Sensitivity and specificity of one-hour pad test as a predictive value for female urinary incontinence. Urol Int. 2008; 81(2): 153-159, doi: 10.1159/000144053, indexed in Pubmed: 18758212.

26. Urinary incontinence and pelvic organ prolapse in women: management. NICE guidance. https://www.nice.org.uk/guidance/ng123/chapter/Recommendations\#assessing-urinary-incontinence.

27. Urinary Incontinence. European Association of Urology Guidelines 2019. https://uroweb.org/guideline/urinary-incontinence/\#3_7.

28. Fusco F, Abdel-Fattah M, Chapple CR, et al. Updated Systematic Review and Meta-analysis of the Comparative Data on Colposuspensions, Pubovaginal Slings, and Midurethral Tapes in the Surgical Treatment of Female Stress Urinary Incontinence. Eur Urol. 2017; 72(4): 567-591, doi: 10.1016/j.eururo.2017.04.026, indexed in Pubmed: 28479203.

29. Palos CC, Maturana AP, Ghersel FR, et al. Prospective and randomized clinical trial comparing transobturator versus retropubic sling in terms of efficacy and safety. Int Urogynecol J. 2018; 29(1): 29-35, doi: 10.1007/s00192-017-3495-0, indexed in Pubmed: 28971224.

30. Blaivas JG, Simma-Chiang V, Gul Z, et al. Surgery for Stress Urinary Incontinence: Autologous Fascial Sling. Urol Clin North Am. 2019; 46(1): 41-52, doi: 10.1016/j.ucl.2018.08.014, indexed in Pubmed: 30466701.

31. Mahdy A, Ghoniem G. Autologous rectus fascia sling for treatment of stress urinary incontinence in women: A review of the literature. Neurourol Urodyn. 2018; 38(S4): 51-58, doi: 10.1002/nau.23878.

32. Sohlberg EM, Elliott CS. Burch Colposuspension. Urol Clin North Am. 2019; 46(1): 53-59, doi: 10.1016/j.ucl.2018.08.002, indexed in Pubmed: 30466702.

33. Rehman $\mathrm{H}$, Bezerra $\mathrm{CCb}$, Bruschini $\mathrm{H}$, et al. Traditional suburethral sling operations for urinary incontinence in women. Cochrane Database Syst Rev. 2011(1) [2017???]: CD001754, doi: 10.1002/14651858.CD001754. pub3, indexed in Pubmed: 21249648.

34. Abraham N, Vasavada S. Urgency after a sling: review of the management. Curr Urol Rep. 2014; 15(4): 400, doi: 10.1007/s11934-014-0400-y, indexed in Pubmed: 24515329.

35. Gomes $\mathrm{CM}$, Carvalho FL, Bellucci $\mathrm{CH}$, et al. Update on complications of synthetic suburethral slings. Int Braz J Urol. 2017; 43(5): 822-834, doi: 10.1590/S1677-5538.IBJU.2016.0250, indexed in Pubmed: 28266818. 